\title{
Migration: sociocultural context of a study
}

\author{
Ivan Koshel $^{1 . *}$, and Marina Yakovenko ${ }^{2}$ \\ ${ }^{1}$ State Budgetary Professional Educational Institution of the Republic of Crimea Kerch Technological \\ College, Ordzhonikidze Street, 2, Kerch, 298313, Republic of Crimea, Russia \\ ${ }^{2}$ Institute of Personnel Training State Employment Service of Ukraine, Novovokzalnaya Street, 17, \\ 03038, Kyiv, Ukraine
}

\begin{abstract}
The article is devoted to a consideration of a migration process as the one that is influencing formation of a modern society. Migration is a factor of modern cultural and social transformations. It is emphasized that migration processes are growing, covering various directions of a society activity. Migration processes are also qualitatively changing society structure and predetermines its directions of development. The necessity to study migration processes from the socio-cultural point of view was substantiated. Emphasis is placed on the motivational factors of migration. The cultural models of migration inherent to migrants on an individual level are presented as a hypothesis guiding sociological cognition in this aspect of scientific knowledge. These include "exodus", "escape", "emancipation", "domination" and "return". The models reflect sociocultural orientations and subjectively perceived migration objectives. The models consider a number of social attitudes and directions for selfrealization of a migrant personality in a new system of social relations.
\end{abstract}

\section{Introduction}

Migration is one of the fundamental factors in the history of formation of human communities, an organic part of social relations. Its specificity is that the social structure of countries, both in global and local dimensions, was formed not only through economic and technological progress, but also under the influence of large-scale social movements.

During different historical epochs migration waves change depending on the scale of social and cultural transformations. In the modern world, migration arises as a result of uneven economic development of countries, environmental disasters, and transformations of public policy. At the present stage it is also caused by aggravation of interethnic and interstate contradictions, general growth of instability and social tension both inside individual countries and on continents. These processes include many economic, political, military, national, cultural, religious and other factors acting both individually and collectively. Therefore, today social movements are an indicator of progress and regression, both global and regional, this indicator reflects the real problems in all spheres of a social life.

\footnotetext{
* Corresponding author: sergiiblack@gmail.com
} 
Migration is the most important tool not only for economic modernization, but also for social and cultural modernization as well. Migration processes are a challenge to all societies, because the diversity of their ethnic cultures is growing and the familiar life practices have to adapt to new living conditions that are changing. Cultural factors in the transformation of social institutions play a decisive role in both individual and mass behavior. In general, it is a complex social process involving many unequal needs, motives, interests and goals of communities and individuals. Thus, A. Dmitriev believes that migration can be regarded as "a sensitive indicator of explicit and hidden social processes, as a monitoring of real and potential phenomena, as a sensitive basis for predicting the dynamics of society as a result of something immeasurably larger than the search for a material resource" [1].

\section{Method}

Social movements have been in the field of attention of scientists for more than a century, but with the passage of time and social perturbations, changes in the multicultural picture of the world, the complexity of globalization processes, attention to them is only increasing. The prevailing view of scientists is that migration is inevitable and cannot be prevented. Therefore, in the "epoch of migration" there is a need and attempts to answer the questions: is it possible to do without mass migrations, should we counteract them and protect the former social patterns, how to adapt migrants, correctly understand their cultural code, how to study new cultural communities, how to direct and use the potential of migration processes, etc. Therefore, the socio-cultural aspect of migration processes is an urgent problem of modern humanitarian knowledge. Taking into account the fact that "sociocultural environment is a social and territorial community", which "reveals the peculiarities of functioning of cultures of different groups of population" [2], arises the question of a deep study of various cultural manifestations of migrants, including psychological features of ethnics and cultures.

Within the framework of sociological thought, a sociocultural approach becomes in demand, on the basis of which "the study of migration from the talk of territorial mobility turns into the study of problems of constructing a new social reality" [3].

Today, due to the need to adapt to new migration conditions, their forms and habitual life practices are changing. Thus, the globalization of modern societies has led to the emergence of new life support systems associated with a dynamic international division of labor, which has led to new scales of migration. The world has shifted from individual strategies to mass migration strategies, which now acts as a prerequisite for many other processes. Migration itself is no longer an exceptional situation for a society or an individual, but a part of a new way of life. A new social layer of the "nomad of globalization" is emerging. (both rich and poor) - a category of people who constantly move, keeping the customs and traditions of the different cultures they come from. A new category is also being formed - "transnational migrants", people who feel equally well in their homeland and in other countries, easily adaptable in the culture of the host countries.

In connection with migration, new social problems also arise - the possibility of strengthening cultural glocalization, which is expressed in the coexistence of different trends. Thus, on the one hand, national and regional cultural differences disappear, ethnic and cultural specifics merge and unify, and on the other hand, the local peculiarity of norms and values of a particular cultural tradition is formed.

Multicultural diversity due to migration processes has also become a problem, forming a polarization of the socio-cultural space. At the same time, new social problems are also emerging - the possibility of creating glocal "lacunas" in which monocultural environments will be reproduced, oriented to perform specific economic and even political functions in 
both global and regional communities. The process of polarization of the socio-cultural space has also became a problem (fig.1). Thus, in large cities multicultural environments are developing, which simultaneously unite monocultural ones, while in peripheries monocultural environments prevail.

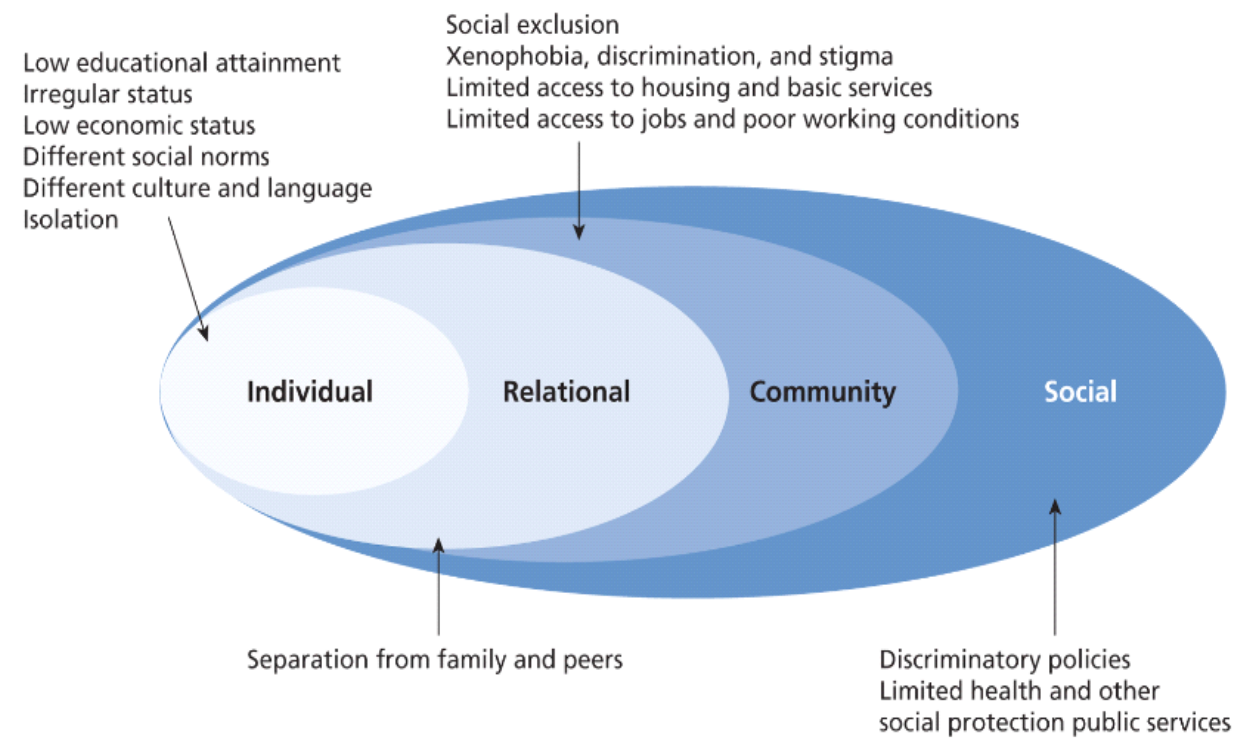

Fig. 1. Policy measures required to tackle the social determinants of health for migrants and ethnic minorities by Ingleby D.

\section{Results}

Thus, entire regions experience "experiences of social experiences of migration situations that allow differentiating flows of social and cultural events into actual contemporary contexts" [4].

A special role is played by the socio-cultural component of migration processes, which requires a new vision of migration as a social process that forms a modern society, which becomes a recipient of new cultural codes - complexes of values and norms, behavioral stereotypes, models of interpersonal communication. At the same time, it is necessary to study the socio-cultural impact of migration processes on donor societies, which are also transformed as a result of outgoing migration flows. This problematics implies clarification of theoretical approaches in connection with the contexts of the current situation and, if necessary, development of new ones. All this is impossible without a firm reliance on the existing experience of sociological conceptualization of migration, without using the heuristic potential of existing concepts, theories and methods.

The social and cultural consequences of migration traditionally include the following:

- changes in the ethnocultural composition of the population in host regions;

- increased social tension, as an instrument of identity protection, caused by the growth of cultural differences;

- aggravation of interethnic relations; formation of new ethnic diasporas;

- the formation of trends in cultural assimilation, integration or cultural and political separatism; 
- development of a network of ethnic entrepreneurship, which affects the content of labor relations and intercultural interactions;

- change in the quality of human capital of the country (region);

- expansion of the shadow sector of economy at the expense of illegal migrants and emergence of the "subculture of illegality".

This approach describes the structural and functional socio-cultural impact of migration on society by migrants, but does not reveal the specific motivational factors of migration. The basis for this analysis can be the theory of E. Ravenstein, who, based on the laws of migration has interpreted migration as a continuous process caused by four main groups of factors. Those act in the place of a migrant's residence, at the stage of his or her movement, in the immediate place of entry into the country, and on a personal level [5]. The theory of migration networks, proposed by sociologist D. Massey [6] allows to describe the mechanism of internal dynamics of migration processes, explaining the formation of stable links between countries of destination of migrants and countries of origin at the individualkin level. When a certain number of migrants have already settled in the destination country, they begin to use the forces of social interaction based on kinship or ethnic proximity. An information flow from the migrants who have already left to those relatives, neighbors and acquaintances who have stayed in their home country is generated to facilitate their decision to migrate [8-11].

Migration networks are understood as established personal ties between migrants, former migrants and non-migrants in countries of departure and countries of entry based on kinship, acquaintance and common place of origin. In other words, migration networks connect compatriots living in their home countries and in other countries to form specific cultural environments. Migration networks also call migrants' social capital, based on which the latter can more easily decide on migration. The social networks of migrants have acquired in modern conditions such a scale that they can be considered as a global factor contributing to the increase of migration flows.

From our point of view, it is also appropriate to consider the cultural impact of migration in terms of the value-added perceptions of migration that are inherent to the direct participants in migration networks. It is necessary to investigate the patterns of sociocultural behavior in the process of social movement that are inherent to individuals. This requires appropriate theoretical tools that take into account the socio-cultural conditionality of migrants' behavior at all stages of migration.

As a scientific hypothesis that orients sociological cognition in migration processes, it is necessary, in our opinion, to study different models of the culture of migration as a special social action, inherent to actors on an individual level. This can include cultural models of migration set by centers of cultural influence on migrants at all stages of social movement related to religious, political, economic institutions, cultural codes of everyday life. The models of social movement determine the social behavior of the migrant and the nature of his interaction with the socio-cultural environment of the society to which he arrives.

It is convenient to analyze the integration indicators using modern information technologies [7-8]. From our point of view, such cultural patterns of migration as "exodus", "flight", "emancipation", "domination", and "return" can be attributed to them. These models reflect the inherent sociocultural orientations of specific individuals that arise in the process of their transition to the state of migrants, and also imply the study of various subjectively realized goals of migration at the worldview level. In the framework of the models, the socially conscious attitudes and directions of self-realization, some of them are vital (reflect the basic aspects of preservation of life), some of them are socio-psychological (reflect the attitude to the cultural, social, political and ideological environment), some political and some are economic (reflect the ideas about the desired future). Each of these models can be shaped in a wide range from asocial to prosocial behavior, be the basis of 
both socially acceptable and socially unacceptable self-expression of the migrant's personality.

\section{Discussion}

In order to present this approach, let us consider some features of the abovementioned cultural migration models [7-14].

1. The cultural model of an "outcome" is a complex of values based on the eschatological picture of the world. Carriers of such a model see their migration as part of rescuing their own group, nation or people from adverse historical circumstances. These may be circumstances related both to the real situation in a particular society of the representatives of the ethnic group to which the individual belongs, and to the imaginary situation resulting from information manipulation among migrants. The reality or imagination of these circumstances does not matter in terms of social behavior of the migrant, both in the process of migration and in the socio-cultural space of the final point of social movement. This kind of cultural paradigm orients the migrant towards the aspiration to achieve public recognition of his special status as a representative of an ethnic group, makes him sensitive to positive manifestations towards the country of emigration or its inherent ethnic characteristics.

2. The cultural model of a "flight" is formed in the process of social conflict development, being its component or phase. It bears the imprint of this conflict, as if transferring it into a new socio-cultural environment. This model contains a kind of cultural code that makes the migrant sensitive to everything related to the existing or potential conflict. In addition, this model may be oriented towards the continuation of the conflict, but from the migrant's point of view, it may be aimed at supporting certain forces and consolidating on this basis in the country of residence with people related to the conflict. At the same time, this cultural model can also focus on complete alienation from one's "former" life and a deeper understanding of the values, norms and rules of life in the new society. In this case, an individual will be inclined to seek maximum distance not only from macro- but also from microconflict-affected communities.

3. The model of an "emancipation" is a reflection of dissatisfaction with an individual's stay in certain socio-economic conditions $[12,14]$. It orients the migrant to the perception of a new social environment in terms of its possibilities in disclosing social potential and implementing those value and normative qualities that could not be implemented in the society from which he migrated. This model makes the individual sensitive to the sociocultural peculiarities and mechanisms of social control of the new living environment. Emancipation allows not only social and psychological emancipation from the familiar but not acceptable economic and political "layering", but also partial or total acceptance of the new environment. At the same time, this cultural model orients it towards self-realization within the framework of the opportunities provided by the recipient country and the circle of communication formed in the new socio-cultural environment.

4. The model of "domination" is an individual picture of the world created by a migrant, assuming a leading position of the individual outside the traditional cultural context. It orients the individual towards a new sociocultural environment in which he or she perceives it as a resource for realizing his or her own life's claim to leadership. A migrant oriented within the framework of such a model will strive to implement his own socio-cultural ideas, and consider the new life environment as having no value of its own, but only the most adequate field for the realization of his ideas.

5. The model of a "return" may be related to an individual's migration back to a sociocultural environment called his or her "historical homeland" on the basis that his or her ancestors, the people to which he or she belongs, or previous generations of his or her 
family lived there. This model has the most pronounced "spiritual", sensual origin. This orientation may aim an individual to restore historical memory, moral rehabilitation and historical justice in his or her own sense, and to realize property restitution. At the same time, this model can also focus on the implementation of experience and knowledge learned in other socio-cultural environments for the development of society, which the resettled person considers his historical homeland.

\section{Conclusion}

The described models can be considered as ideal types reflecting the properties of a particular migrant personality, forming a living combination in the structure of her consciousness. Considering the typical combinations one can describe the real existing group features of migrants according to their socio-cultural orientations, it should be possible to establish the nature and potential of their socio-cultural influence on the society that accepts them. Each of these hypothetical models can be realized in different moduses of individual social action.

It should be noted that any model is multi-factored, it presupposes different types of implementation, determined both by the specific personality of the native from a certain socio-cultural environment and by the specific historical conditions of its immersion in the cultural environment of the host community.

The study of these models, as well as related strategies and social scenarios of different types of personality behavior that manifest themselves in migration, will describe the subjective factors that form the systems of social relations that develop in the migration flows. This will allow to better understand their social orientation and determine sociocultural potential. The new knowledge, in turn, will improve the tools and strategies of practical work-organize and guide a full dialogue with migrants more effectively. This will also help to take into account the specifics of motivation of their social behavior.

The study of socio-cultural problems of migration is also necessary for predicting and regulating both "traditional" and new flows of migrants. At the state level, this will contribute to the improvement of cultural policy, focused on the effective adaptation of migrants in a new social and cultural environment. This will also help in their cultural enrichment.

In conclusion, we emphasize that social movements in any country of the world play huge socio-economic and political role. However, at the current stage of social development, when migration currents have turned into powerful multicultural flows, the cultural specificity of migration plays a significant role in the formation of social culture both globally and locally, as it changes not only the social structure of societies, but also its ethnic composition, religious dominance, of the country's citizens qualitative composition, but also sets the trend of a particular society development.

\section{References}

1. A. Dmitriev, Territorial'naya Migraciya: Filosofskij i Konfliktologicheskij Aspekty (December 2008) https://texts.news/etnosotsiologiya-istoriya/territorialnayamigratsiya-filosofskiy-44871.html (as of Sep 02, 2020)

2. N. Pobeda, Sociologiya Kul'tury (Astroprint, Odessa, 223, 1997)

3. Z. Hot, O. Chistyakova, Vestnik AGU, 3, 139-146 (2017)

4. A. Kuropyatnik, Vestnik RUDN, 16(3), 496-510 (2016)

5. E. Ravenstein, Journal of the Statistical Society, 46, 167-235 (1885) 
6. S. Douglas Massey, Population Index, 56(1), 3-26 (1990)

7. A. Zhilenkov, S. Chernyi, International Journal Of Embedded Systems, 11(6), 806 (2019) DOI: 10.1504/ijes.2019.104005

8. S. Chernyi, V. Budnik, Methods for optimizing solutions when considering group arguments by team of experts (2017) DOI: 10.1063/1.5009873

9. N. Crooks, A. Wise, T. Frazier, Social Science \& Medicine, 263, 113303 (2020) doi: 10.1016/j.socscimed.2020.113303

10. R. Niu, K. Lu, X. You, System, 74, 38-49 (2018) doi: 10.1016/j.system.2018.02.006

11. H. Phan, B. Ngu, R. Lin, H. Wang, J. Shih, S. Shi, Heliyon, 5(10), e02550 (2019) doi: 10.1016/j.heliyon.2019.e02550

12. T. Tegtmejer, Culture And Social Interaction, 17, 79-89 (2018) doi: 10.1016/j.lcsi.2018.01.001

13. M. Labella, Clinical Psychology Review, 59, 1-15 (2018) doi: 10.1016/j.cpr.2017.10.006

14. Q. Wong, J. Chen, B. Gregory, et al., Journal Of Affective Disorders, 243, 165-174 (2019) doi: 10.1016/j.jad.2018.09.028

15. S. Sardareh, M. Saad, Procedia - Social And Behavioral Sciences, 66, 343-353 (2012) doi: 10.1016/j.sbspro.2012.11.277 